\title{
MODEL OF INDIVIDUAL TACTICAL TRAINING OF ATHLETES IN GAME SPORTS
}

\author{
Mariia Leonteva, Vladimir Guba, Andrey Rodin
}

\begin{abstract}
The analysis of age-related features of individual tactical training of athletes in sports games is crucial in improving sportsmanship. The results of the study are presented, justifying the biomechanical, intellectual, psychophysiological and control components of the formation of effective game actions, ensuring the achievement of high individual tactical skills in the process of conducting competitive struggle. The generalized criteria for the integral preparedness of the players at the stages of sports training, determining the nature of the improvement of the sports form in the annual training cycle.
\end{abstract}

Key words: competitions, tactics, model, movements, age periodization, individual actions, integrated preparedness.

\section{INTRODUCTION}

The basis of gaming activity in sports games is a variety of motor actions that allow you to solve specific tactical problems in the competition. The effectiveness of motor actions of athletes in game sports, in many respects, is determined by the player's ability to quickly recognize various game situations and use certain technical methods on this basis (Kozin, Kugaevsky, 2014; Rodin, Zakharov, Artyugin, 2017; Khrustalev, 2013).

Achieving a high level of sportsmanship by a player involves the formation of knowledge and practical experience with the help of the concept of the formation of motor actions, which should include a methodology for identifying game situations based on a principle action scheme: perceiving a game episode by means of symbolic forms, analyzing the characters at the level of formation of the concept of the character, reflecting it in consciousness and execution in practical activity with the help of technical techniques in solving individual

The modern practice of game sports requires experts to accurately differentiate time periods in order to improve individual tactical skills, however, the available technical techniques in solving individual tactical tasks problems (Guba, 2010; Makarov, Churkin, 2008) The modern practice of game sports requires experts to accurately differentiate time periods in order to improve individual tactical skills, however, the available sources of special scientific and methodological literature address very general issues related to the general- ization of the organization and planning of training athletes in the context of a long-term sports and pedagogical process (Lebed, 2005; Legonkov, 2003).

The purpose of research - develop and prove the effectiveness of the model of individual tactical training of athletes in game sports.

\section{METHODOLOGY}

The study was conducted during 2009-2018, in which 122 athletes of various qualifications took part, among which (24 young volleyball players) of the primary training groups of the Kuzbass volleyball school (Kemerovo), 20 basketball players of sports specialization school № 7 in Smolensk, 32 volleyball players groups for improving sportsmanship sports specialization school of A.B. Savina (Obninsk, Kaluga Region) and 46 athletes of student teams of the Smolensk State Academy of Physical Education and Sports, which are members of the Association of Student Basketball and the Student Volleyball League of Russia.

In the course of the study, an analysis of special and scientific-methodical literature was carried out, pedagogical observations were carried out with elements of video filming and the use of automated complexes Data Volley 2007, Data VideoPro and InfoBasket 2.5; pedagogical experiment (ascertaining and formative); biomechanical analysis of the kinematics of motor actions using the UltraMotion Pro SPORT hardware-software complex; functional diagnostics including the 
use of the spirographic complex KM-AR-01 and the software "Diamond - S"; psychophysiological diagnostics was presented by the hardware-software complex "NS-PsychoTest", developed by the specialists of Neurosoft LLC; modeling. The results obtained during the study were processed and interpreted using methods of mathematical statistics.

The main components of the experimental model of individual tactical training of athletes in playing sports in the long-term training process were:

- the introduction of biomechanical control of the kinematic characteristics of the motor actions of players in the process of training and competitive activity, which allows you to determine the rational technique of game reception; provides knowledge about the features of performing technical methods of the opponent's game in the process of implementing individual tactical actions in attack and defense; contributes to the effective management of movements based on the correction of their actions depending on the actions of the opponent

- introduction of innovative teaching methods "game tasks" and "coaching keys" into the training process, which allow to identify the game situation and effectively model the solution to a tactical task.

- the use of functional and psychophysiological diagnostics in the process of competitions and training activities, allowing to establish the relationship between the effectiveness and versatility of motor actions in game situations, taking into account changes in indicators of physical and intellectual fitness.

- implementation of the leading display method aimed at expanding the stability, variability and cost-effectiveness of performing motor actions in a specific game situation.

- the use of analysis and synthesis as a theoretical approach, which allows to form a specialized conceptual apparatus and thesaurus of motor actions on the basis of the information received in the context of solving tactical problems in various game situations.

\section{RESULTS AND DISCUSSION}

Summarizing the data of preliminary studies, it should be noted that the individual tactical training of athletes in game sports is determined by the age periods of effective training, which allows achieving high sports results in sports. The basis of individual tactical movements of athletes in game sports is determined by the biomechanical, intellectual, psychophysiological and managerial components of the model, which has its own structure and sequence of action schemes in the game process.

An analysis of the data indicates that in the process of formation of effective motor actions for athletes of playing sports of the EG as a result of the application of the developed concept, the possibilities of the kinematic structure of the motor actions of playing techniques significantly increased depending on the actions of the opponent (spatial, temporal and spatial-temporal characteristics) in the process of competitive and training activity compared with the CG $(p<0.05)$.

It was revealed that the use of the method of game tasks and coaching keys in the training process of EG athletes allowed the formation of special knowledge and the sign structure of game situations, which allowed achieving significantly higher indices of individual tactical actions in attack and defense compared to the CG of sports athletes ( $\mathrm{p}$ $<0.05)$.

It was established that as a result of the introduction of differentiated physical activity and specialized exercises in the formation of effective motor actions, EG athletes allowed the end of the match to perform techniques with significantly greater efficiency, versatility and variability in the kinematic structure of game techniques against the background of physical and psychophysiological fatigue (in terms of the function of external respiration and simple visual-motor reaction) compared with CG $(\mathrm{p}<0.05$; Table 1$)$. 
Table 1. Indicators of external respiration during the formation of a ball to the basket for basketball players of sports specialization groups (16-18 years) of the EG and the $C G$ at the specially preparatory $(S P)$ and pre-competitive stages (PRS) of sports training

\begin{tabular}{|c|c|c|c|c|c|}
\hline Stage & Groups & Actual data, L & $\%$ & $\mathrm{p}$ & Level \\
\hline \multirow{3}{*}{ SP } & EG & $\begin{array}{l}5,03 \\
5,67\end{array}$ & $\begin{array}{l}95,79 \\
99,25\end{array}$ & \multirow{3}{*}{$\begin{array}{l}>0,05 \\
<0,05\end{array}$} & $\begin{array}{l}\text { Standard } \\
\text { Standard }\end{array}$ \\
\hline & CG & $\begin{array}{l}4,92 \\
4,58\end{array}$ & $\begin{array}{l}94,03 \\
92,37\end{array}$ & & \multirow{2}{*}{$\begin{array}{l}\text { Standard } \\
\text { Standard }\end{array}$} \\
\hline & $\mathrm{p}$ & $\begin{array}{l}<0,05 \\
>0,05\end{array}$ & $\begin{array}{l}<0,05 \\
>0,05\end{array}$ & & \\
\hline \multirow{3}{*}{ PRS } & EG & $\begin{array}{l}5,73 \\
6,74 \\
\end{array}$ & $\begin{array}{r}99,89 \\
109,33 \\
\end{array}$ & \multirow{3}{*}{$\begin{array}{l}<0,05 \\
<0,01\end{array}$} & $\begin{array}{c}\text { Standard } \\
\text { Above standard }\end{array}$ \\
\hline & CG & $\begin{array}{l}4,50 \\
3,80\end{array}$ & $\begin{array}{l}91,90 \\
84,36\end{array}$ & & \multirow{2}{*}{$\begin{array}{c}\text { Standard } \\
\text { Below standard }\end{array}$} \\
\hline & $\mathrm{p}$ & $\begin{array}{l}<0,05 \\
<0,05\end{array}$ & $\begin{array}{l}<0,05 \\
<0,05\end{array}$ & & \\
\hline
\end{tabular}

Note: the upper value in the fraction is the indicators before the experiment; the lower value is after the experiment.

Using the proposed model allowed EG athletes to classify game situations in attack and defense and, on the basis of certain motor actions of the opponent expressed in sign forms, to find a more optimal solution to the game situation in the process of individual tactical actions in comparison with KG athletes, the training process of which is based on the Federal Standard sports training and sample training programs for the selected sport $(\mathrm{p}<0.05)$.

\section{CONCLUSION}

The introduction of an experimental model of individual tactical training into the multi-year training process for sports athletes allows achieving higher levels of game action in attack and defense. This is due to the fact that, as a result of the formation of effective motor actions, athletes have a stable kinematic structure of playing techniques, a high level of functional preparedness and a psychophysiological state, which make it possible to implement a technical technique during competitions with high efficiency. The application of the method of game problems, coaching keys and leading display in the process of formation of effective motor actions for volleyball and basketball players, can significantly increase the level of sportsmanship of players in competitive activity.

The presented model of individual tactical training of athletes has been successfully tested in experimental conditions and has proved its effectiveness. In this regard, it is advisable to recommend the presented model to specialists as an effective and universal approach to the preparation of a sports reserve in game sports.

\section{REFERENCES}

Guba, V.P. (2010). Modernization of the theory and methodology of sports games, Theory and practice of physical education, Moscow, pp. 16-19.

Kozin, V.V., Kugaevsky, S.A. (2014). Training in motor actions of young athletes in playing sports, Physical Education: Education, Education, Training, Moscow, pp. 39-43.

Lebed, F. (2005). "Formula of the game": the general theory of sports games, education and training, Volgograd.

Legonkov, S.V. (2003). Methods of teaching the technical methods of playing volleyball, Smolensk, pp.72

Makarov, Yu.M., Churkin, A.A. (2008). Didactic aspects of initial tactical training in sports, Olympus, St. Petersburg.

Rodin, A.V., Zakharov, P.S., Artyugin, S.V. (2017). Correction of the structure of motor actions of qualified basketball players using the methodological method "trainer keys", Physical education: upbringing, education, training, Moscow, pp. 13.

Khrustalev, G.A. (2013). Theoretical and methodological foundations of modeling competitive activity in sports games, Tula.

\section{Corresponding authors:}

Leonteva Mariia Sergeevna,

Doctor of Pedagogics, Associate Professor, 105122. Moscow, Sireneviy bulvar street 4, building 1 , E-mail: leontyeva72@mail.ru 